\title{
Effect of Growth Hormone Treatment with Noonan Syndrome: Experience from Kabi International Growth Study (KIGS/ICGS)
}

Patrick Wilton and Barto Otten on behalf of the International Board of the Kabi International Growth Study

Department of Clinical Research, Peptide Hormones (PW), Stockholm, Sweden and Department of Paediatrics, University Hospital, Sint Radboud (BO), Nijmegen, The Netherlands

Abstract 55 children, 34 males, 21 females, with Noonan syndrome (NS) included in the Kabi Pharmacia International Growth Study were treated with growth hormone (GH) in a median dose of $0.6 \mathrm{IU} / \mathrm{kg} /$ week. Median age at start of treatment was 10.6 years and median height standard deviation score (SDS) was -3.1. Pretreatment height velocity was $4.3 \mathrm{~cm} /$ year and during the first, second and third years it increased to 7.0,6.0 and $4.8 \mathrm{~cm} /$ year respectively. Projected adult height with Noonan specific standard increased from -0.4 SDS to 0.3 SDS at the end of three years' treatment. No adverse reactions were reported.

Key words: Noonan syndrome, growth hormone, efficacy, safety.

\section{Introduction}

NS was differentiated from the UllrichTurner syndrome in 1963 by pediatric cardiologists (1). The incidence has been estimated to be around 1/2,500 live births (2). One of the characteristics of NS is short stature. Growth curves describing the natural growth in this syndrome have been published $(3,4)$. The final height has been reported to be 163 and $153 \mathrm{cms}$ in males and females respectively (4). GH secretion has been reported to be within normal limits but serum concentrations of IGF-I were low $(5,6)$. Pilot studies have reported

Correspondence: Dr.Patrick Wilton, Pharmacia, Peptide Hormones, 112 87, Stockholm Sweden experiences with $\mathrm{GH}$ treatment in children with NS (5-10). The Kabi International Growth Study, KIGS, was initiated in 1987 to follow the efficacy and safety of GH treatment in children. The purpose of this paper is to report the outcome of up to six years of $\mathrm{GH}$ treatment in 55 children with NS included in the KIGS.

\section{Patients and Methods}

Data from 55 patients, 34 males, 21 females given a diagnosis of NS was available. Height and weight SDS were calculated according to the standards of Tanner et al. (11) and the Noonan specific standards of Ranke et al. (4). Birth weight and length SDS were calculat- 
ed using the standards of Wälli et al. (12). Weight-for-height was calculated as the percentage of ideal weight for a given height at a chronological age among the normal population. Bone age estimations using the standard of Greulich and Pyle (13) were performed by the investigators. Adult height predictions were performed with the method of projected final height (14) using the standards of Ranke et al. (4). In the statistical analysis the KruscalWallis test was used.

\section{Results}

The auxological characteristics of the patients at start of GH therapy are presented in Table 1. Birth weight and length were within normal limits as was target height. The median age at GH start was 10.6 years. The median height SDS was -3.1 compared to the standard of Tanner and -1.0 compared to the

Table 1 Clinical characteristics at start of GH treatment.

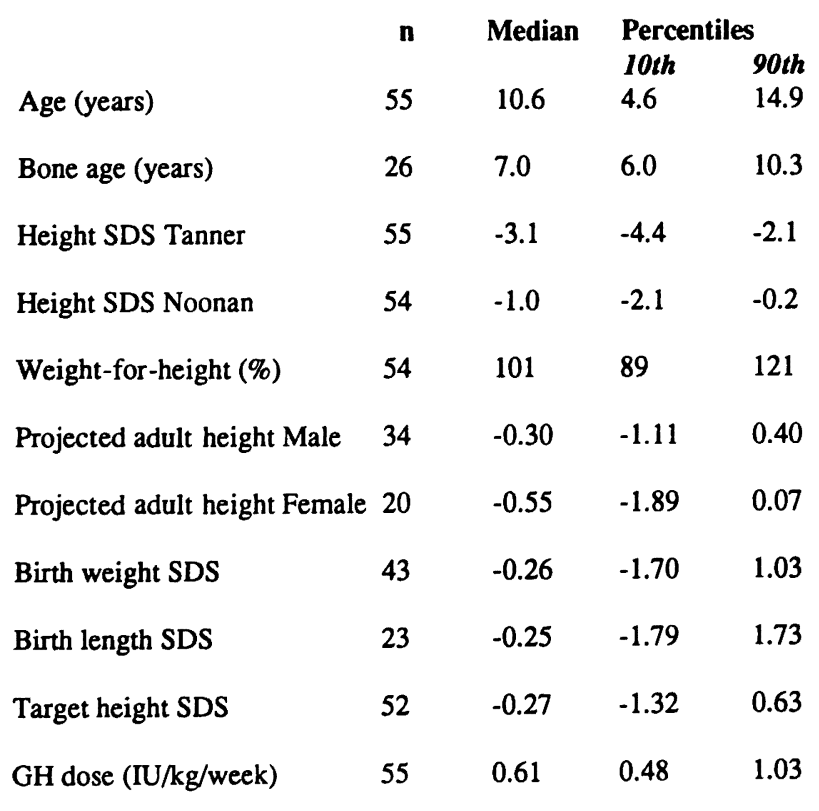

Noonan standard. Individual heights compared to the Noonan specific standard are shown in Fig. 1 and 2 for boys and girls respectively. The median projected adult height was -0.30 in the males and -0.55 in the females.

Bone age was retarded in all investigated children (Fig. 3). GH stimulation test was reported in 46 patients and in 17 the GH peak was below $20 \mathrm{mU} / \mathrm{L}$.

The median dose of GH at start of treatment was $0.6 \mathrm{IU} / \mathrm{kg} /$ week and remained rather constant throughout the treatment. Median frequency of injections was six/week.

The auxological data during the first three Height at start of treatment (Tonner)
Males

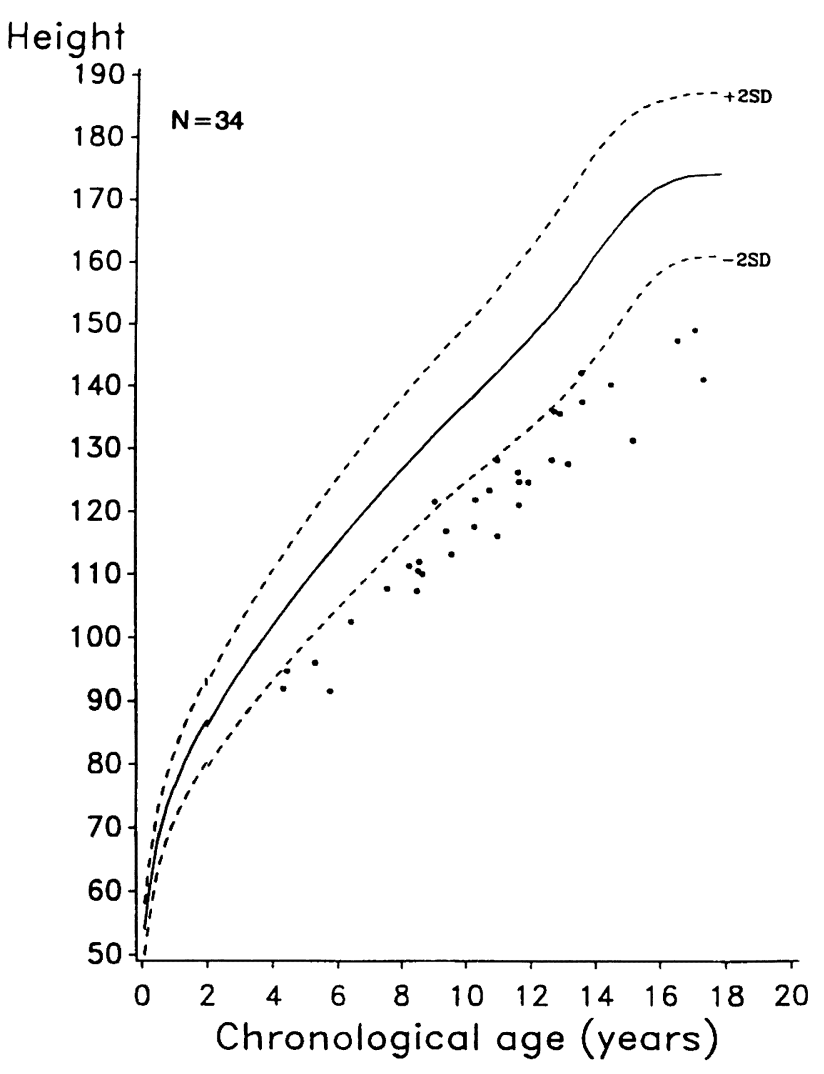

Fig. 1 Height in 34 boys with NS at start of GH treatment. Reference according to Tanner 1966. 


\section{GH treatment in Noonan Syndrome}

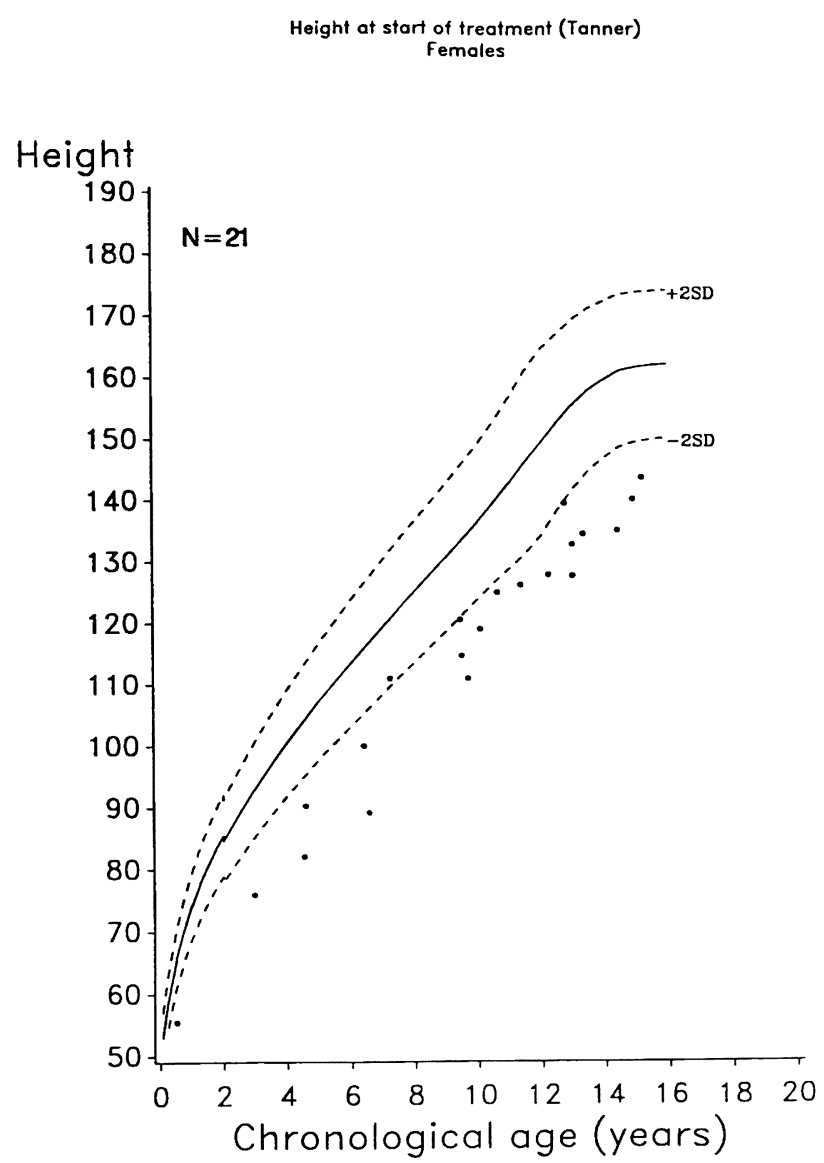

Fig. 2 Height in 21 girls with NS at start of GH treatment. Reference according to Tanner 1966.

years of GH treatment are shown in Table 2. The median height velocity was $4.3 \mathrm{~cm} /$ year the year before treatment and increased to 7.0, 6.0

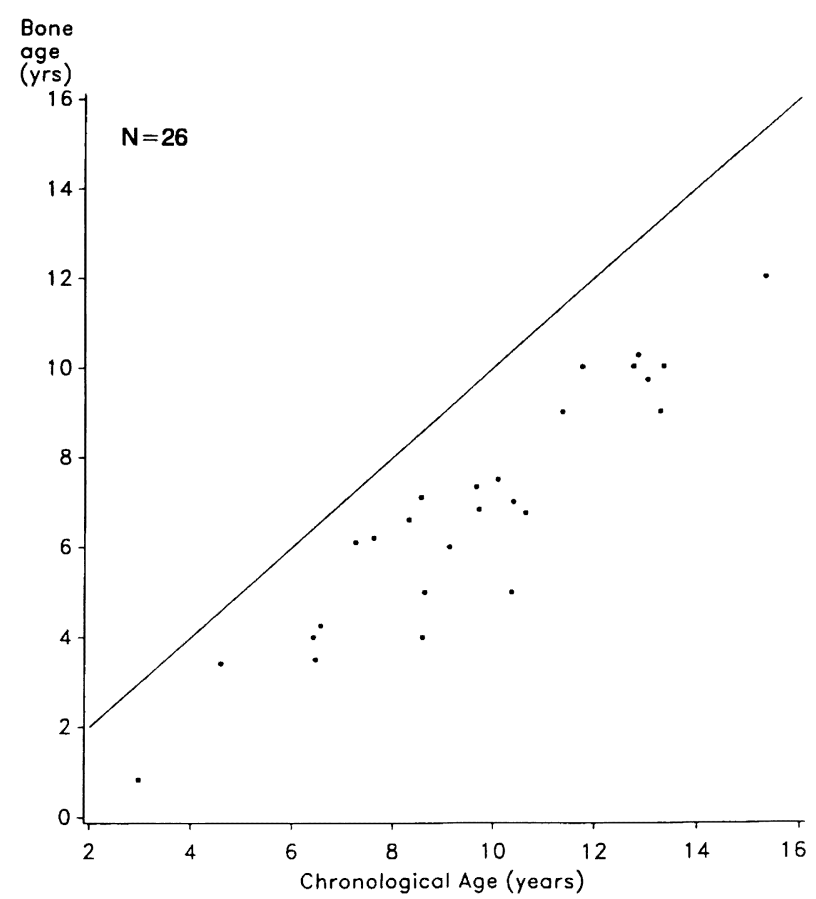

Fig. 3 Bone age versus chronological age in 26 patients with NS, line of identity is shown.

and $4.8 \mathrm{~cm} /$ year during first three years of treatment (Fig. 4). Eleven children were treated for three years and their median height SDS (Tanner) increased from -2.8 to -2.4 and their projected final height SDS (Ranke) increased from -0.3 to +0.3 during the three years of treatment.

No adverse reaction was reported.

Table 2 Auxological characteristics during three years of GH treatment.

\begin{tabular}{|c|c|c|c|c|c|c|c|c|c|}
\hline \multirow[b]{3}{*}{ Height SDS } & \multicolumn{3}{|c|}{ 1st year } & \multicolumn{3}{|c|}{ 2nd year } & \multicolumn{3}{|c|}{ 3rd year } \\
\hline & $n$ & median & $(10-90 t h)$ & $n$ & median & (10-90th) & $n$ & median & (10-90th) \\
\hline & & & & & & & & & \\
\hline Tanner & 44 & -2.6 & $(-3.8,-1.9)$ & 24 & -2.5 & $(-3.6,-1.6)$ & 11 & -2.4 & $(-3.7,-1.2)$ \\
\hline Noonan & 46 & -0.8 & $(-1.8,0.5)$ & 26 & -0.5 & $(-1.5,0.7)$ & 11 & 0.2 & $(-1.3,0.7)$ \\
\hline $\begin{array}{l}\text { Height velocity } \\
\text { (cm/year) }\end{array}$ & 46 & 7.0 & $(5.4,9.1)$ & 26 & 6.0 & $(3.5,8.5)$ & 11 & 4.8 & $(4.2,7.7)$ \\
\hline
\end{tabular}




\section{Wilton et al.}

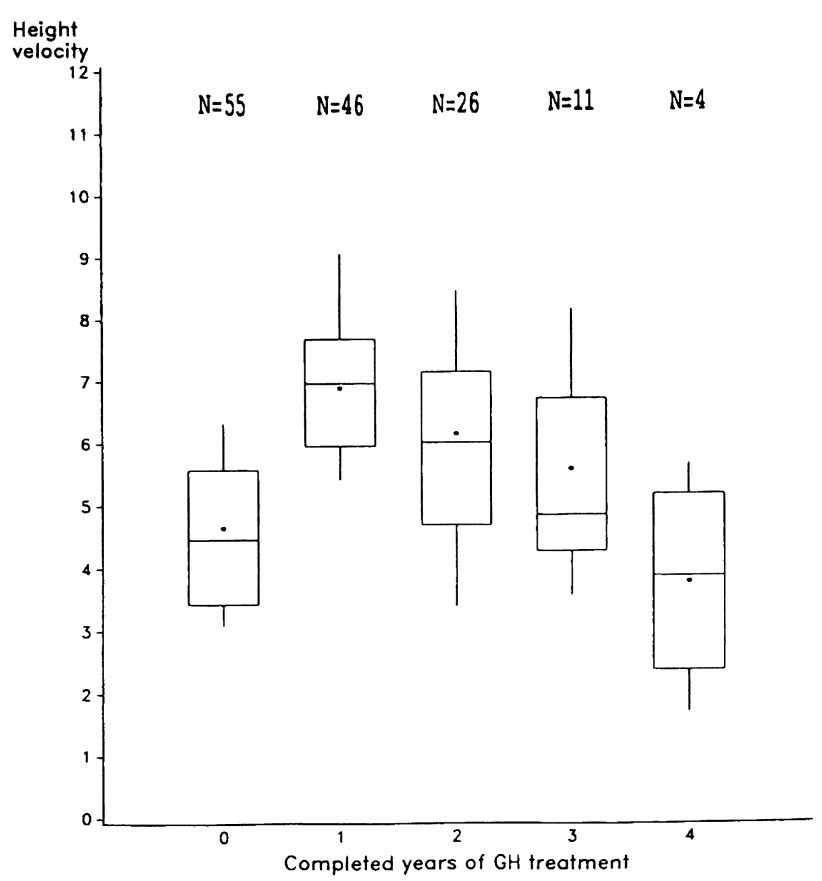

Fig. 4 Height velocity $(\mathrm{cm} /$ year) at start of treatments and during first four years of GH. Box represents median, 75 th and 25 th centile. Star represents the mean and vertical lines 10 th and 90th centiles.

\section{Discussion}

In contrast to Turner syndrome there is no objective method for diagnosing NS. There are however, scoring systems developed for the diagnosis of it $(15,16)$. The diagnosis of the patients in this report is most probably correct so there must be other reasons for the finding that the height is below what has been reported in this syndrome. The most important reason is likely to be that it is the shortest children who are considered for treatment. Most of the tested patients had a GH response which can be considered normal. Despite this there was a significant growth promoting effect of GH. The increase in height velocity is usually more pronounced in Turner syndrome during $\mathrm{GH}$ treatment compared to the present findings. But the dose of GH used in the Turner syndrome is usually higher than the actual median dose of $0.6 \mathrm{IU} / \mathrm{kg} /$ week. With a higher dose of $\mathrm{GH}, 28 \mathrm{IU} / \mathrm{m}^{2} /$ week (corresponding to about $1.0 \mathrm{IU} / \mathrm{kg} /$ week) a very good growth response (10 $\pm 0.5 \mathrm{~cm} /$ year) has been reported in 14 children with NS (Dunger, personal communication). The findings in the actual analysis from the KIGS enhance the published suggestion that GH safely increases linear growth in children with NS.

\section{References}

1. Noonan J, Ehrmke D. Associated non-cardiac malformations in children with congenital heart disease. J Pediatr. 1963; 63: 468-70.

2. Nora J, Fraser F. Medical Genetics: Priciples and Practice, 2nd ed Philadelphia, Lea and Febiger, 1981.

3. Witt DR, Keena BA, Hall JG. (1986) Growth curves for height in Noonan syndrome. Clin Genet 30: 150-3.

4. Ranke MB, Heidemann P, Knupfer C. (1988) Noonan syndrome: growth and clinical manifestions in 144 cases. Eur J Pediatr 148: 220-7.

5. Ahmed ML, Foot ABM, Edge JA. (1991) Noonan's syndrome: abnormalities of the growth hormone/IGF-I axis and the response to treatment with human biosynthetic human growth hormone. Acta Paediatr 80: 446-50.

6. Cianfarim S, Spadoni G, Finocchi. Treatment with growth hormone in 3 cases of Noonan syndrome. Minerva Pediatr. 1987; 


\section{GH treatment in Noonan Syndrome}

39: 281-4.

7. Cotterill A, Mc Kenna W, Elsauri M. The effect of growth hormon therapy on linear growth and cardiac morphology in short children with Noonan syndrome. Pediatr Res. 1993; 33: A240 543

8. Thomas B, Stanhope R. Long term treatment with growth hormone in Noonan syndrome. Acta Paediatr 1993; 82: 853-5.

9. Lu PW, Cowell B, Moore A. Growth hormone therapy in Noonan syndrome. Proceedings from 11th International Symposium, Stockholm April 1991.

10. Matsuo K, Nakatsuka K, Aoki Y. Noonan syndrome: Auxological and endocrinological investigation. Clin Pediatr Endocrinol Suppl 4 1994: 93-7.

11. Tanner JM, Whitehouse RH, Takaishi M. (1966) Standards from birth to maturity for height, weight, height velocity and weight velocity: British children, 1965. Arch Dis
Child 41: 454-71, 613-35.

12. Wälli R, Stetter T, Largo RH. Gewicht, Länge und Kopfumfand neugeborner Kinder und ihre Abhängigkeit von mutterlichen und kindlichen Faktoren. Helv Paediatr Acta 35: 397-418.

13. Greulich W, Pyle SI. (1959) Radiographic atlas of skeletal development of hand and wrist, Stanford University Press, Stanford, CA.

14. Lyon AJ, Preece MA, Grant DB. (1985) Growth curve for girls with Turner's syndrome. Arch Dis Child 60: 932-5.

15. Duncan WJ, Fowler RS, Farkes LG. (1981) A comprehensive scoring system for evaluating Noonan syndrome. Am J Med Genet 10: 37-50.

16. Sharland M, Burch M, McKenna WM, Paton MA. (1992) A clinical study of Noonan syndrome. Arch Dis Child 67: 17883. 